\title{
O Brincar de Mães e Bebês com e sem Histórico de Sofrimento Psíquico
}

\author{
Patricia Menezes Schmittt, Sabrina Felin Nunes ${ }^{2}$, \\ Anaelena Bragança de Moraes ${ }^{3}$, Ana Paula Ramos de Souza ${ }^{4}$
}

\begin{abstract}
RESUMO
Objetivo: Analisou-se a evolução do brincar em bebês com e sem risco psíquico e sua relação com o desenvolvimento infantil dos 9 aos 24 meses. Estudo quantitativo, observacional, retrospectivo. Método: A obtenção dos dados foi por meio do roteiro de análise do brincar, elaborado nesta pesquisa. Foram observados os aspectos cognitivos do brincar do bebê, a relação intersubjetiva e a análise do investimento materno. Avaliaram-se 32 bebês e suas mães. Foram utilizados os indicadores clínicos de referência/risco ao desenvolvimento infantil e os Sinais Preaut para detecção do risco psíquico. Resultados: Houve associação significativa da diminuição do prazer e empenho maternos no brincar e do prazer infantil com objeto com a presença de risco psíquico. O uso criativo do objeto emerge mais tardiamente no grupo com sofrimento psíquico. Conclusão: As crianças com sofrimento psíquico e suas mães apresentaram menos construções criativas no brincar em relação às sem sofrimento psíquico.
\end{abstract}

Palavras-chave: Brinquedo. Desenvolvimento infantil. Fatores de risco. Linguagem. Cognição.

\section{THE PLAY OF MOTHERS AND BABIES WITH AND WITHOUT A HISTORY OF PSYCHIC SUFFERING}

\begin{abstract}
Objective: It was analyzed the evolution of play in babies with and without psychic risk and the relationship with child development from nine to 24 months. Method: The study is quantitative, observational and retrospective. The data were obtained through the play analysis script, prepared for the research. The cognitive aspects of baby play, intersubjective relation and analysis of maternal investment were observed. Thirty-two children and their mothers were evaluated by child development clinical indicators of reference/risk and the PREAUT Signs were used to detect the psychic risk. Results: There was a significant association in the child's pleasure with the object, as well as the pleasure and commitment of the mother in the play with psychic risk group. The creative use of the object in children appears late in group with psychi suffering Conclusion: Psychically distressed children and their mothers had fewer creative constructs compared to those without suffering.
\end{abstract}

Keywords: Play. Child development. Risk factors. Language. Cognition.

\footnotetext{
${ }^{1}$ Terapeuta Ocupacional graduada pela Universidade Franciscana (UFN). Residência Multiprofissional em Atenção e Gestão Hospitalar (UFSM, Santa Maria, RS, Brasil). Mestrado em Distúrbios da Comunicação Humana (UFSM). http://lattes.cnpq.br/1133587384521849. https://orcid.org/0000-0002-4239-690X. patriciamschmitt22@gmail.com

${ }^{2}$ Fisioterapeuta graduada pela Universidade Franciscana (UFN). Doutorado em Distúrbios da Comunicação Humana (UFSM, Santa Maria, RS, Brasil). http:// lattes.cnpq.br/5109379582763715. https://orcid.org/0000-0001-5976-9760. sah_felin@hotmail.com

${ }^{3}$ Doutorado em Epidemiologia - Universidade Federal do Rio Grande do Sul - UFRGS. Professora titular - Universidade Federal de Santa Maria, Santa Maria, RS. http://lattes.cnpq.br/4262448037922838. https://orcid.org/0000-0002-6578-0613. anaelena@smail.ufsm.br

${ }^{4}$ Fonoaudióloga. Pós-Doutorado em Linguística (UFRGS). Docente dos Programas de Pós-Graduação em Distúrbios da Comunicação Humana e em Psicologia da Universidade Federal de Santa Maria - UFSM, Santa Maria, RS. http://lattes.cnpq.br/7859963389320763. https://orcid.org/0000-0003-4733-0632. ana. souza@ufsm.br
} 


\section{INTRODUÇÃO}

O desenvolvimento infantil é composto por aspectos estruturais e instrumentais. Os estruturais relacionam-se às bases biológicas e psíquicas à emergência do psiquismo, tanto do ponto de vista afetivo quanto cognitivo (CORIAT; JERUSALINSKY, 1996). Os instrumentais abrangem a psicomotricidade, a linguagem (enquanto comunicação) e as atividades de vida diária, entre outros aspectos inclusos no brincar e cotidiano infantil (PERUZZOLO; SOUZA, 2017). Nessa perspectiva, o brincar compõe o setting terapêutico da terapia ocupacional e da fonoaudiologia.

O brincar constitui-se por meio de gestos espontâneos e criativos da criança, e assume, na primeira infância, um papel de fundamental relevância quando se consideram os aspectos psíquicos, cognitivos e de linguagem (VENDRÚSCOLO; SOUZA, 2015). Ele contribui significativamente para a afetividade na vida das crianças e construção da realidade do próprio corpo e dos objetos do mundo, sendo fundamental à constituição do psiquismo (WINNICOTT, 1975).

0 brincar pode refletir características indicativas de uma estruturação psicopatológica, como o autismo, na qual se evidenciam dificuldades na troca entre a mãe ou sua substituta e a criança em razão das dificuldades de intersubjetividade primária infantil (KLINGER; SOUZA, 2015). Ele pode refletir o risco psíquico e associar-se a fatores sociodemográficos e psicossociais, como apontam diversos estudos (VAN HOOGSTRATEN; MORAES; SOUZA, 2018a; CRESTANI et al., 2013; CRESTANI; MORAES; SOUZA, 2015; KRUEL; SOUZA; 2018; VENDRUSCOLO; SOUZA, 2015).

Enquanto aspecto fundamental do cotidiano infantil, o brincar é um espaço de intervenção privilegiado na clínica da Terapia Ocupacional e da Fonoaudiologia com bebês, pois está presente na avaliação bem como na terapia de crianças que apresentam alguma alteração no desenvolvimento (CAMPOS et al., 2017). O brincar é considerado uma ação livre e subjetiva na criança, permeada por prazer e curiosidade (SANT'ANNA; BLASCOVI-ASSIS; MAGALHÃES, 2008). Nesse sentido, a sua utilização qualifica as avaliações e intervenções terapêuticas. Diante da ideia de que o brincar possui importância enquanto parte da ocupação cotidiana da criança, afirma-se que as atividades lúdicas são consideradas terapêuticas, considerando as particularidades de cada faixa etária, pois oportunizam o exercício da criatividade e personalidade infantis (FONSECA; SILVA, 2015; SOUZA et al., 2009).
Especificamente no campo da Fonoaudiologia, o brincar assume uma posição simbólica que ancora o funcionamento da linguagem, pois instiga a criança a ocupar seu turno de fala, estabelecendo, assim, um impulso para o diálogo. Essa atividade, no entanto, poderá ser instável a depender das condições ambientais da criança. Por isso, ao analisar o brincar de uma criança é necessário ampliar o olhar para o que a criança pode realizar e como o ambiente a sustenta neste brincar (POLONIO; FREIRE, 2008).

Considerando tais aspectos teóricos, esta pesquisa objetivou analisar a evolução do brincar em bebês com e sem risco psíquico e a sua relação com o desenvolvimento infantil nas faixas etárias dos 9 aos 24 meses.

\section{MATERIAIS E MÉTODOS}

Esta pesquisa é um estudo de coorte retrospectivo, do tipo observacional e descritivo, com abordagem quali-quantitativa. Foi aprovado pelo Comitê de Ética e Pesquisa sob o número de CAEE: 28586914.0.0000.5346 e parecer número 652.722. Nesta investigação foi utilizado um banco de dados da pesquisa "Análise comparativa do desenvolvimento de bebês prematuros e a termo e sua relação com risco psíquico: da detecção à intervenção".

As avaliações que compuseram este estudo foram realizadas por meio de uma equipe interdisciplinar do grupo de pesquisa previamente treinado para tal, constituído por três psicólogas, duas fonoaudiólogas, duas fisioterapeutas e uma terapeuta ocupacional.

Para a realização das filmagens e avaliações, a criança e a mãe compareciam ao local da coleta no horário estabelecido na Unidade Básica de Saúde. Quando havia algum impedimento da família em se deslocar até a unidade, a coleta ocorria em suas residências. Os responsáveis pelas crianças foram contatados no dia do Teste do Pezinho em uma Unidade Básica de Saúde e Ihes foram explicados os objetivos e procedimentos da pesquisa. Uma vez de acordo em participar, assinaram o Termo de Consentimento Livre e Esclarecido e responderam a uma entrevista semiestruturada acerca de variáveis sociodemográficas, psicossociais familiares e obstétricas do bebê participante. No decorrer das coletas também foi realizada uma entrevista continuada para verificar se havia modificações no ambiente familiar.

Para a presente pesquisa foram escolhidos os bebês nascidos a termo para, deste modo, eliminar possíveis atrasos relativos à prematuridade. Foram 
excluídos também bebês com suspeitas de alteração do desenvolvimento, ou alterações confirmadas que decorressem de lesões biológicas e também crianças com mães ou substitutas com psicopatologia grave. Tais avaliações foram feitas pela equipe de pesquisa e, quando necessárias, encaminhadas a especialistas em genética, neurologia ou psiquiatria.

A amostra constou de 32 bebês nascidos a termo e suas respectivas mães, que compareceram a todas as etapas de coleta previstas para a elaboração desta pesquisa. Analisou-se, portanto, as filmagens da interação mãe-bebê em situação de brincadeira dos 9 aos 24 meses.

Etapa $1-8$ meses e 1 dia a 9 meses e 29 dias: avaliação dos Indicadores Clínicos de Risco/Referência ao Desenvolvimento Infantil (Irdi) fase II, e dos Sinais Preaut, bem como a realização de filmagem do dia de bebê-mãe em situação de brincadeira com boneca, mamadeira, panelinhas, meios de transporte, animais e pequena bola (KUPFER et al., 2010; OLLIAC et al., 2017), e filmagem de dez minutos com a mãe e bebê e cinco minutos com a examinadora, de modo que a câmera estava posicionada em frente à criança, diante do espelho fixado na parede da sala.

Etapa 2-11 meses e 1 dia a 12 meses e 29 dias: reavaliação do roteiro Irdi fase III e filmagem nas mesmas condições da etapa 3 .

Etapa 3-17 meses e 1 dia a 18 meses e 29 dias: avaliação do roteiro Irdi etapa IV; avaliação do MCHAT e filmagem nas mesmas condições das etapas 3 e 4 (MURATORI, 2014). Avaliação do Bayley III, aspectos motor, de linguagem e cognitivo, realizada por fisioterapeuta habilitada.

Etapa 4-23 meses e 1 dia a 24 meses e 29 dias: avaliação do MCHAT, avaliação do Bayley III e filmagem nas mesmas condições das etapas 1, 2 e 3 (BAYLEY, 2006). O Quadro 1 traz a ilustração das etapas.

Cabe destacar que os Indicadores Clínicos de Referência/Risco ao Desenvolvimento Infantil (Irdi), instrumento escolhido para realizar a comparação entre os grupos sem e com risco porque abrange diversas psicopatologias e avalia os bebês de zero a 18 meses, uma vez que os Sinais Preaut, realizados aos quatro e nove meses, e o Modified Checklist for Autism in Toodlers MCHAT, aplicado aos 18 e 24 meses, são protocolos mais direcionados à detecção de autismo, uma subcategoria no grupo com risco psíquico identificado pelo Irdi. Os sinais Preaut buscam avaliar o fechamento do terceiro tempo do circuito pulsional, através da observação das competências do bebê e trocas prazerosas com a mãe. A seguir, o resumo das perguntais iniciais do protocolo, cuja pontuação 15 identifica criança fora de risco psíquico, abaixo de 5 com risco para autismo e entre 5 e 15 com risco de outra psicopatologia (VAN HOOGSTRATEN; SOUZA; MORAES, 2018b):

Sinal 1: O bebê procura olhar para você (examinador): a) espontaneamente (sim - 4 pontos, não - zero); b) quando você fala com ele (protoconversação): (sim 1 ponto, não - zero).

Sinal 2: O bebê procura se fazer olhar por sua mãe ou substituta: a) sem qualquer estimulação (sim - 8pontos, não - zero); b) quando ela fala com ele (protoconversação): (sim - 2 pontos, não - zero).

O roteiro de análise do brincar da criança e da mãe que compôs a análise das filmagens deste estudo, foi construído pelas pesquisadoras do grupo de pesquisa. Este instrumento precisou ser desenvolvido considerando etapas cognitivas a partir da visão piagetiana, que inclui o brincar sensório-motor, o uso funcional de objetos e o simbolismo com faz de conta, acrescidos de uma análise de aspectos afetivos, como ter prazer no brincar (NOVAES; BARZAGHI, 2014; GRAÑA, 2008; SAINT-GEORGES et al., 2011). $\mathrm{Na}$ análise do comportamento materno estão previstos procedimentos como intrusividade, diretividade e linguagem, ritmo de oferta dos brinquedos, entre outros.

Após realizadas as análises, foi construído, em planilha do Excel, um banco de dados para cada faixa etária analisada. A análise estatística foi realizada com o auxílio do aplicativo computacional Statistica 9.1. Além da análise descritiva, foi utilizado o teste Exato de Fisher, considerando o nível de significância $5 \%$. No Quadro 1 está sintetizado o roteiro.

\section{RESULTADOS}

Analisando os dados dos participantes deste estudo foi possível traçar um perfil da amostra, constituída, por conveniência, de 32 crianças nascidas a termo que completaram as filmagens até 24 meses. Destas, $56,2 \%$ eram do sexo masculino e $43,8 \%$ do sexo feminino.

Observou-se que 13 crianças apresentaram risco psíquico pelo protocolo Irdi e 7 pelos sinais Preaut. Cabe ressaltar que essas 7 crianças, identificadas pelos sinais Preaut e 4 entre essas 7 pelo MCHAT, estavam contidas no grupo identificado por meio do roteiro Irdi.

Na Tabela 1 estão as frequências das categorias do brincar, considerando os 19 bebês sem risco pelo roteiro Irdi e os 13 bebês com risco psíquico. 
Quadro 1 - Roteiro para Análise do Brincar

\section{ANÁLISE DO BRINCAR DA DÍADE MÃE-BEBÊ}

1 - EXPLORAÇÃO DE OBJETOS: Nesse primeiro tópico foi realizada a análise da criança a fim de identificar se ela apresenta ou não a permanência do objeto. Os itens analisados foram:

a. Consegue explorar objetos com sua mão - possui preensão efetiva.

1.2 - Consegue explorar objetos com sua boca.

1.3 - Consegue buscar objetos com movimentos espontâneos.

1.4 - Tem prazer com a experiência física com o objeto. Consideramos o prazer quando a criança apresentava uma expressão facial com sorriso e atenção ao objeto, bem como contato visual estabelecido.

1.5 - Busca um objeto com o olhar prestando atenção em um estímulo sensorial que vem dele.

2 - USO FUNCIONAL DOS OBJETOS: Nesse tópico foi analisado se a criança é capaz de imitar alguma ação do adulto e também atribuir significado aos objetos, utilizando-os na sua função observada no mundo.

2.1 - Quando a mãe brinca com algum objeto a criança imita a sua ação (imitação com modelo).

2.2 - A criança explorando os brinquedos, quando vê algum em específico, atribui significado a esse brinquedo sem o modelo materno (imitação retardada).

2.3 - Utiliza o objeto no seu uso funcional.

3 - EMERGÊNCIA DO FAZ DE CONTA: Nesse item foi observado se a criança apresenta uma inteligência representacional, portanto se é apta a representar internamente algumas ações por meio de invenções.

3.1 - Quando havia uma situação imaginária criada pela criança e que poderia envolver a representação de papéis traduzida em uso criativo do objeto.

3.2 - Faz construções criativas e novas com o objeto, montando uma cena completa, imaginando uma pequena história.

\section{4 - ANÁLISE DO COMPORTAMENTO MATERNO}

Intrusividade: Condição que não permite a criança explorar o objeto interrompe a brincadeira, ou seja, a criança organiza uma ação e é interrompida pela mãe.

4.1 - Quando a criança explora um objeto a mãe a deixa ter a experiência sem oferecer outro - intrusividade ausente.

4.2 - Quando a criança explora um objeto, a mãe não a deixa ter a experiência - Intrusividade presente.

Diretividade: Mãe não permite à criança brincar livremente, direciona a brincadeira a partir de suas escolhas, sem o consentimento da criança.

4.3 - A mãe aceita a proposta de brincadeira da criança, respeitando seu desejo sem impor sua proposta de brincar diretividade ausente.

4.4 - A mãe não aceita a proposta de brincadeira do filho, forçando-o a brincar do que ou como ela quer.

Linguagem: Observou-se como a mãe comunica-se durante o brincar com a criança, se nomeia os brinquedos que oferece à criança e se descreve as brincadeiras que estão sendo realizadas durante o brincar de modo natural (diálogo que acompanha naturalmente) a partir de dois itens:

4.5 - A mãe nomeia objetos que oferece à criança.

4.6 - A mãe descreve a ação que está sendo desenvolvida.

Ritmo de oferta dos brinquedos: Foi avaliado qual é o ritmo de oferta de brinquedos novos na exploração por parte da mãe ao bebê.

4.7 - Ritmo Adequado: Oferece o objeto e dá tempo para a criança explorá-lo livremente.

4.8 - Ritmo Rápido: Oferece de maneira rápida o objeto; um, logo o outro, sem deixar a criança explorar livremente.

4.9 - Ritmo Lento: Lentidão no ritmo de oferta do objeto, oferecendo e convocando pouco a criança.

5 - Demonstra empenho/prazer na atividade com o filho: consideramos como prazer a expressão materna por meio do sorriso facial, tom de voz e contato visual estabelecido com o filho. 


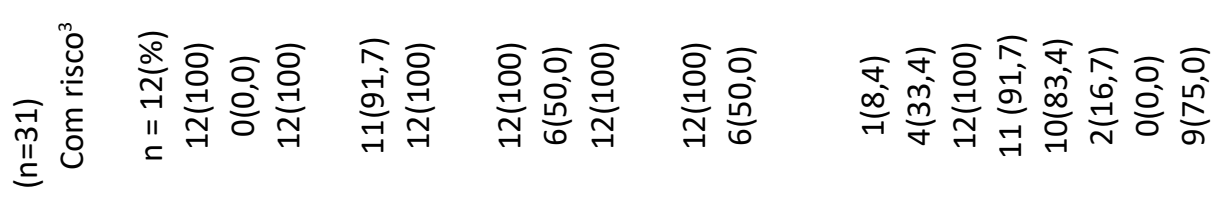

凹్

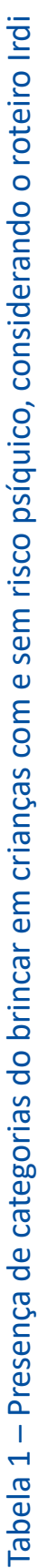

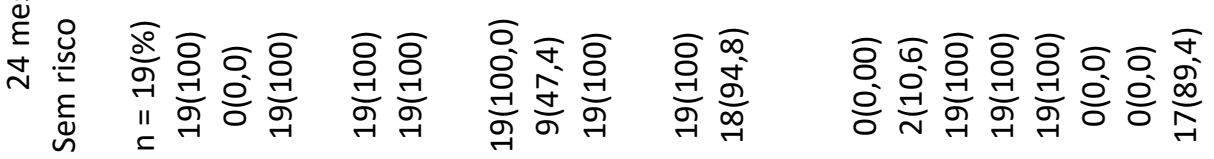

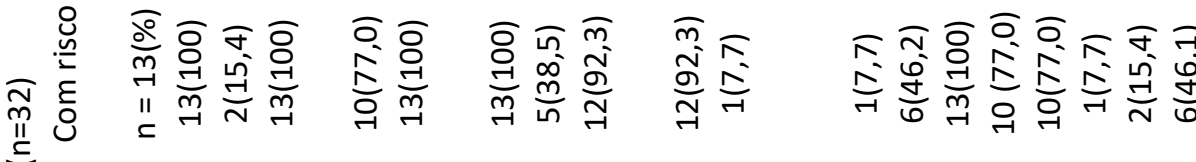
岁

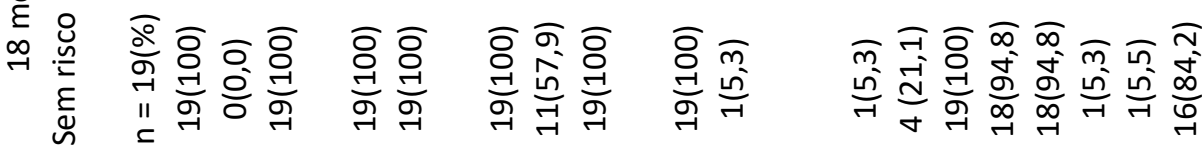

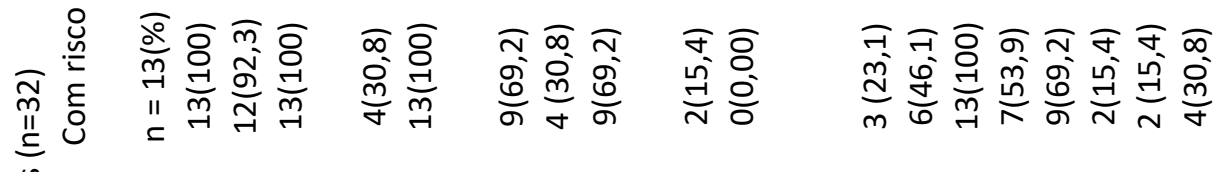
위

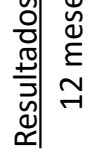

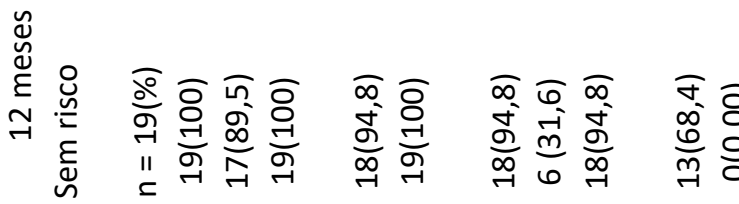

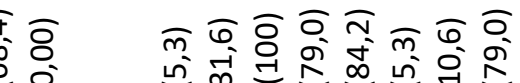

产

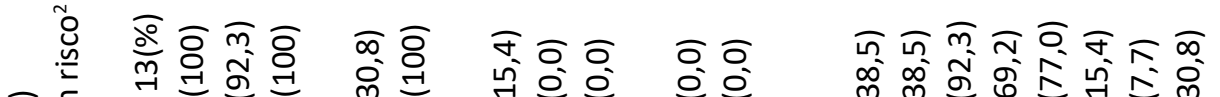
尛

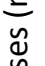

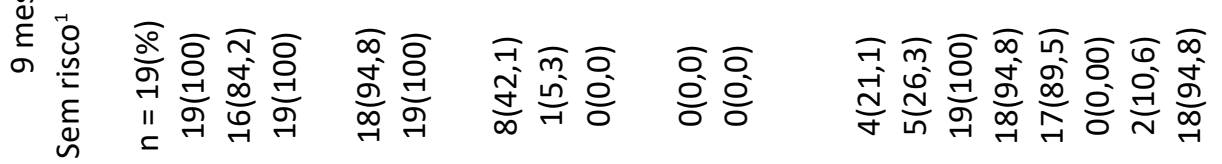

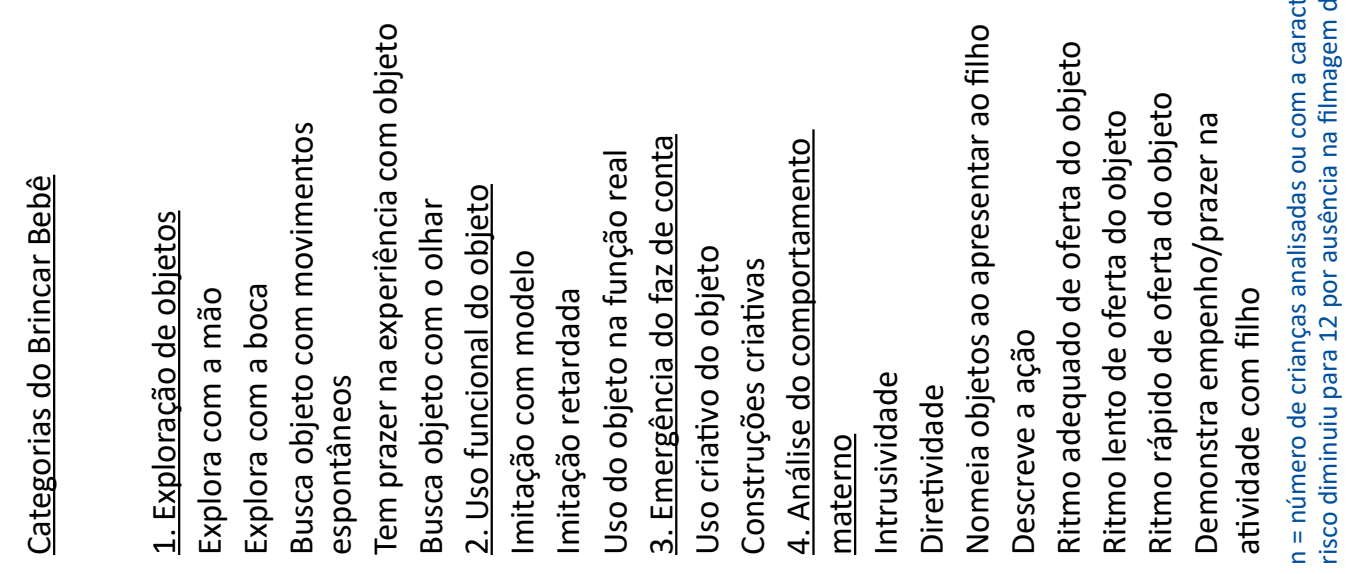


A análise dos vídeos evidenciou uma evolução geral das crianças em termos da emergência das categorias analisadas. Pode-se identificar que, quanto à exploração de objetos, todos os bebês utilizam a mão, fizeram movimentos espontâneos, demonstrando intenção de pegar o objeto, e direcionaram o olhar ao objeto em todas as idades. Já a exploração com a boca foi realiza pela maior parte dos bebês entre 9 e 12 meses, mas cessou a partir dos 18 meses.

A categoria ter prazer na exploração do objeto foi identificada na maior parte dos bebês sem risco psíquico aos 9 e 12 meses, e em apenas 30\% da amostra dos bebês com risco psíquico. Este prazer com o objeto emergiu em quase todos os bebês, ou seja, $91,7 \%$ aos 18 e 24 meses, período em que se apresentaram mais atentos à descoberta dos objetos e também de sua função, tanto no quesito imitação com o modelo quanto para uso do objeto em sua função habitual.

Apenas a imitação retardada não surgiu plenamente até o final do segundo ano de vida ( $50 \%$ das crianças com risco e $47 \%$ das crianças sem risco). Este dado evidencia que alguns bebês ainda estavam desenvolvendo habilidades de memória e representação da função dos objetos. Quanto ao uso criativo dos objetos, observou-se o início desta característica aos 12 meses e sua presença mais evidente aos 18 e 24 meses, mas o mesmo não foi visto em termos de construções criativas, categoria ainda pouco frequente aos dois anos.

Quanto às categorias que se referem ao comportamento materno, evidenciaram-se características como a intrusividade em grau mais elevado nas mães dos bebês que apresentaram risco psíquico (38,5\% aos 9 meses), sintoma que foi se reduzindo ao longo dos meses. Desta forma, aos 24 meses somente 8,4\% manifestam essa característica.

Com relação à diretividade materna, observou-se semelhança nos dois perfis de crianças nos 9 e 24 meses, porém aos 18 e 24 meses essa caraterística ficou reduzida nas mães de crianças que não apresentavam risco, mas permaneceu presente nas mães das crianças em risco psíquico.

A partir da análise das categorias maternas com relação a nomear objetos que oferecem à criança e descrever ações durante a brincadeira, evidenciou-se que todas as mães, dos diferentes perfis, nomeiam os objetos, porém o que as diferencia é que as mães das crianças com risco descrevem menos as ações na brincadeira entre 9 e 12 meses quando comparadas às crianças sem risco psíquico. $O$ que se observou foi que há certa evolução positiva nesse comportamento materno aos 18 e 24 meses, porém ainda é pequena quando comparada aos resultados das crianças sem risco.

O grupo de mães das crianças com risco apresentou menores percentuais de prazer e empenho na brincadeira com o filho. Identificou-se que somente $30 \%$ apresentaram essa característica no período dos 9 e 12 meses. Já aos 18 e 24 meses esse percentual aumentou, correspondendo a $46 \%$. Esse grupo também evidenciou maior percentual de ritmo lento e rápido na oferta do objeto do que as mães de bebês sem risco psíquico. Esses dados evidenciam maior falta de sintonia na brincadeira na díade mãe-bebê em risco psíquico. Na Tabela 2 são apresentadas as significâncias estatísticas para a associação entre cada categoria do brincar em relação à presença ou não de risco psíquico.

Pode-se observar, na Tabela 2, que houve associação significativa na relação do prazer que a criança expõe na experiência com o objeto. Confirma-se que as crianças que apresentaram risco psíquico possuem uma experiência de menor prazer com o objeto quando comparadas às crianças que não apresentaram risco ao desenvolvimento. Elas começam a evidenciar aumento do prazer na relação com o objeto a partir dos 18 e 24 meses de idade. Cabe destacar que foi identificado um caso que ainda havia dificuldades em ter prazer com o objeto: um menino, que, no decorrer do acompanhamento, foi diagnosticado com autismo.

Concomitante a isso, quando analisado o prazer materno diante do brincar com o filho, percebeu-se que aos 9 e aos 12 meses há muitas mães que não conseguiam ter prazer e apresentavam menor investimento na brincadeira com o filho. No decorrer dos 18 aos 24 meses, essa característica reduziu em alguns casos em que a mãe e o filho demonstraram encontrar-se na brincadeira, mas ainda houve duplas com dificuldade no laço a partir do olhar sobre o brincar.

Pode-se, ainda, observar, na Tabela 2, que houve associação significativa na utilização criativa do objeto e risco psíquico, porque as crianças com risco demoraram mais a evidenciar esta característica (aos 18 meses). Em contrapartida, as crianças sem risco iniciaram aos 12 meses de idade. Quanto às demais categorias, não houve associação estatística significativa quando as categorias do brincar foram relacionadas aos resultados do roteiro Irdi. Esse fato evidencia o que as neurociências afirmam sobre a criatividade estar relacionada ao prazer e também ao que a psicanálise, classicamente, afirma sobre a construção da realidade pela criança. 
Tabela 2 - Significância estatística da associação das categorias entre bebês com e sem risco Irdi

\begin{tabular}{|c|c|c|c|c|}
\hline & $\begin{array}{l}9 \text { meses } \\
*_{p} \text {-valor }\end{array}$ & $\begin{array}{c}12 \text { meses } \\
p \text {-valor }\end{array}$ & $\begin{array}{c}18 \text { meses } \\
p \text {-valor }\end{array}$ & $\begin{array}{c}24 \text { meses } \\
\text { p-valor }\end{array}$ \\
\hline \multicolumn{5}{|l|}{ Categorias da criança } \\
\hline \multicolumn{5}{|l|}{ 1. Exploração de objetos } \\
\hline Explora com a boca & 0,630 & 1,000 & 0,157 & - \\
\hline Tem prazer com objeto & $0,002 *$ & $0,002 *$ & 0,057 & 1,000 \\
\hline \multicolumn{5}{|l|}{ 2. Uso funcional do objeto } \\
\hline Imitação com modelo & 0,140 & 0,131 & - & - \\
\hline Imitação retardada & 1,000 & 1,000 & 0,472 & 1,000 \\
\hline Uso funcional do objeto & - & 0,131 & 0,406 & - \\
\hline \multicolumn{5}{|l|}{ 3. Emergência do faz de conta } \\
\hline Uso criativo do objeto & - & $0,004 *$ & 0,406 & - \\
\hline Construções criativas & - & - & 1,000 & 0,006 \\
\hline \multicolumn{5}{|l|}{ 4. Análise do comportamento materno } \\
\hline Intrusividade & 0,427 & 0,278 & 1,000 & 0,387 \\
\hline Diretividade & 0,700 & 0,473 & 0,243 & 0,173 \\
\hline Nomeia objetos ao apresentar ao filho & 0,406 & - & - & - \\
\hline Descreve a ação & 0,131 & 0,243 & 0,278 & 0,387 \\
\hline Ritmo adequado de oferta do objeto & 0,374 & 0,401 & 0,278 & 0,141 \\
\hline Ritmo lento de oferta do objeto & 0,157 & 0,551 & 1,000 & 0,141 \\
\hline Ritmo rápido de oferta do objeto & 1,000 & 1,000 & 0,551 & - \\
\hline $\begin{array}{l}\text { Demonstra empenho/prazer na atividade com } \\
\text { o filho }\end{array}$ & $0,002 *$ & $0,010^{*}$ & 0,072 & 0,349 \\
\hline
\end{tabular}

*Teste Exato de Fischer

Fonte: As Autoras.

Na Tabela 3 são apresentados os resultados quanto à avaliação dos bebês pelo Bayley III aos 24 meses. Apenas 19 bebês, dos 32, compareceram a esta avaliação.

Pode-se observar, na Tabela 3, que dez crianças sem risco psíquico e nove com risco psíquico realizaram avaliação do Bayley III no desfecho da pesquisa quanto aos aspectos da cognição, linguagem e motricidade. O percentual de alterações de linguagem e cognição foi maior nas crianças com risco psíquico quando comparadas às crianças sem risco psíquico. Já o atraso motor apresentou distribuição diferente no grupo. Enquanto o grupo sem risco psíquico teve uma distribuição de $40 \%$ de atraso, o grupo com risco psíquico teve apenas de $11 \%$, ou seja, o atraso motor foi maior no grupo sem risco psíquico.
Considerando as categorias do brincar, observa-se que as interações linguísticas por nomeação e descrição da ação não foram distintas entre as mães de crianças com e sem risco psíquico e com e sem atraso na linguagem. Outras categorias do brincar, portanto, podem estar conectando-se ao atraso de linguagem, evidenciado por meio do Bayley III. Entre elas observou-se a presença de diretividade e intrusividade como característica comum da maior parte das mães, emergência da imitação com modelo mais tardia na maior parte das crianças e ausência de prazer com o objeto nas primeiras etapas, conforme está descrito nos casos de atraso nos aspectos do Bayley III na Tabela 4.

Tabela 3 - Descrição do desenvolvimento cognitivo, de linguagem e motor no Bayley III aos 24 meses

\begin{tabular}{|c|c|c|c|c|c|c|}
\hline \multirow{3}{*}{$\frac{\text { Irdi }}{\text { Risco Psíquico }}$} & \multicolumn{6}{|c|}{ Bayley III aos 24 meses } \\
\hline & \multicolumn{2}{|c|}{ Cognitivo } & \multicolumn{2}{|c|}{ Linguagem } & \multicolumn{2}{|c|}{ Motor } \\
\hline & $\begin{array}{c}\text { Sem atraso } \\
n(\%)\end{array}$ & $\begin{array}{c}\text { Com atraso } \\
\mathrm{n}(\%)\end{array}$ & $\begin{array}{c}\text { Sem atraso } \\
\mathrm{n}(\%)\end{array}$ & $\begin{array}{c}\text { Com atraso } \\
\mathrm{n}(\%)\end{array}$ & $\begin{array}{c}\text { Sem atraso } \\
\mathrm{n}(\%)\end{array}$ & $\begin{array}{c}\text { Com atraso } \\
\mathrm{n}(\%)\end{array}$ \\
\hline Sem risco $n=10$ & $10(100,0)$ & $0(0,0)$ & $7(70,0)$ & $3(30,0)$ & $6(60,0)$ & $4(40,0)$ \\
\hline Com risco $n=9$ & $6(66,6)$ & $3(33,3)$ & $4(44,4)$ & $5(55,5)$ & $8(88,8)$ & $1(11,1)$ \\
\hline
\end{tabular}

Fonte: As Autoras. 
Tabela 4 - Descrição da evolução do brincar no grupo com atraso em aspecto(s) do Bayley III

\begin{tabular}{|c|c|c|c|c|}
\hline Sujeito & $\begin{array}{l}\text { BAYLEY III } \\
\text { Atrasos }\end{array}$ & Risco Psíquico & $\begin{array}{l}\text { Características alteradas do brincar do bebê no } \\
\text { período }\end{array}$ & $\begin{array}{l}\text { Características } \\
\text { alteradas do brincar } \\
\text { materno no período. }\end{array}$ \\
\hline B1 & $\begin{array}{l}\text { Linguagem e } \\
\text { Motor }\end{array}$ & $\begin{array}{l}\text { Presente } \\
\text { nos três } \\
\text { instrumentos }\end{array}$ & $\begin{array}{l}\text { Apático no brincar e sem prazer; a imitação } \\
\text { com modelo surgiu aos } 9 \text { meses, mas a imitação } \\
\text { retardada não emergiu no período observado. Uso } \\
\text { funcional do objeto emergiu aos } 12 \text { meses, mas o } \\
\text { criativo apenas aos } 18 \text { meses. Construções criativas } \\
\text { surgiram aos } 24 \text { meses. }\end{array}$ & $\begin{array}{l}\text { Mãe empenhava-se } \\
\text { e convocava, mas } \\
\text { diretiva aos } 24 \text { meses }\end{array}$ \\
\hline.$B 2$ & $\begin{array}{l}\text { Linguagem, } \\
\text { Cognitivo e } \\
\text { motor }\end{array}$ & $\begin{array}{l}\text { Ausente } \\
\text { nos três } \\
\text { instrumentos }\end{array}$ & $\begin{array}{l}\text { Prazer em brincar aos } 9 \text { meses e imitação com } \\
\text { modelo; uso funcional e criativo surgiu aos } 12 \text { meses. } \\
\text { Aos } 18 \text { meses faz uso criativo e imitação retardada e } \\
\text { aos } 24 \text { meses construções criativas. }\end{array}$ & $\begin{array}{l}\text { Intrusiva e diretiva } \\
\text { aos } 9 \text { meses. }\end{array}$ \\
\hline B3 & Motor & $\begin{array}{l}\text { Ausente } \\
\text { nos três } \\
\text { instrumentos }\end{array}$ & $\begin{array}{l}\text { Aos } 9 \text { meses já tinha prazer na ação sobre objeto; } \\
\text { imitou com modelo aos } 12 \text { meses e de modo } \\
\text { retardado aos } 18 \text { meses. O uso funcional e criativo } \\
\text { emergiu aos } 12 \text { meses e as construções criativas aos } \\
24 \text { meses. }\end{array}$ & $\begin{array}{l}\text { Mãe apresentou- } \\
\text { se empenhada } \\
\text { e adequada na } \\
\text { interação. }\end{array}$ \\
\hline B4 & Linguagem & $\begin{array}{l}\text { Sim no Irdi e } \\
\text { Preaut }\end{array}$ & $\begin{array}{l}\text { Aos } 9 \text { meses não tinha prazer em brincar. A imitação } \\
\text { com modelo surgiu aos } 18 \text { meses e uso funcional aos } \\
12 \text { meses; uso criativo e construções criativas só aos } \\
24 \text { meses. Imitação retardada esteve ausente em } \\
\text { seus dados. }\end{array}$ & $\begin{array}{l}\text { Intrusiva e diretiva, } \\
\text { não descrevia a ação, } \\
\text { ritmo lento na oferta } \\
\text { do brinquedo. }\end{array}$ \\
\hline B5 & $\begin{array}{l}\text { Linguagem } \\
\text { e motor }\end{array}$ & $\begin{array}{l}\text { Ausente } \\
\text { nos três } \\
\text { instrumentos }\end{array}$ & $\begin{array}{l}\text { Imitação com modelo surgiu aos } 18 \text { meses e a } \\
\text { retardada não emergiu até } 24 \text { meses. O uso funcional } \\
\text { apareceu aos } 12 \text { meses e uso criativo aos } 18 \text { meses. } \\
\text { Construções criativas não emergiram. }\end{array}$ & $\begin{array}{l}\text { Intrusiva e diretiva } \\
\text { aos } 9 \text { e diretiva aos } \\
24 \text { meses. }\end{array}$ \\
\hline B6 & $\begin{array}{l}\text { Linguagem, } \\
\text { cognitivo e } \\
\text { motor }\end{array}$ & $\begin{array}{l}\text { Presente } \\
\text { nos três } \\
\text { instrumentos }\end{array}$ & $\begin{array}{l}\text { Imitação com modelo apareceu aos } 12 \text { meses; } \\
\text { uso funcional e criativo aos } 24 \text { meses, mas não } \\
\text { construções criativas. O prazer com objeto esteve } \\
\text { presente aos } 18 \text { meses, mas não com a mãe. Caso de } \\
\text { risco claro para autismo. }\end{array}$ & $\begin{array}{l}\text { Empenhada } \\
\text { sem alterações } \\
\text { importantes, mas } \\
\text { falava um pouco } \\
\text { rápido por falta de } \\
\text { resposta do filho. }\end{array}$ \\
\hline B7 & $\begin{array}{l}\text { Linguagem e } \\
\text { cognitivo }\end{array}$ & $\begin{array}{l}\text { Presente } \\
\text { nos três } \\
\text { instrumentos }\end{array}$ & $\begin{array}{l}\text { Começou a demonstrar prazer com objeto aos } 18 \\
\text { meses; imitou de modo consistente com modelo aos } \\
18 \text { e } 24 \text { meses e usou funcional e criativamente aos } \\
18 \text { meses. Não fazia construções criativas. }\end{array}$ & $\begin{array}{l}\text { Intrusiva e diretiva } \\
\text { aos } 9 \text { meses e } \\
\text { diretiva aos } 24 \\
\text { meses. }\end{array}$ \\
\hline B8 & Linguagem & $\begin{array}{l}\text { Presente no } \\
\text { Irdi e MCHAT }\end{array}$ & $\begin{array}{l}\text { Imitação com modelo surgiu aos } 12 \text { meses e } \\
\text { retardada aos } 18 \text { meses; o uso funcional do objeto e } \\
\text { criativo surgiu aos } 18 \text { meses, mas não demonstrou } \\
\text { construções criativas com objeto, embora tivesse } \\
\text { prazer desde os } 9 \text { meses. }\end{array}$ & $\begin{array}{l}\text { Intrusiva e diretiva } \\
\text { aos } 9 \text { meses. }\end{array}$ \\
\hline B9 & Linguagem & $\begin{array}{l}\text { Presente no } \\
\text { Irdi }\end{array}$ & $\begin{array}{l}\text { Não demonstrava prazer com objeto aos } 9 \text { e } 12 \\
\text { meses; característica surgiu aos } 18 \text { meses; a imitação } \\
\text { com modelo emergiu aos } 12 \text { meses; o uso funcional } \\
\text { e criativo aos } 18 \text { meses e a imitação retardada, uso } \\
\text { criativo do objeto e construções criativas emergiram } \\
\text { aos } 24 \text { meses. }\end{array}$ & $\begin{array}{l}\text { Intrusiva e diretiva } \\
\text { aos } 9 \text { meses. }\end{array}$ \\
\hline
\end{tabular}




\section{DISCUSSÃO}

Conforme indicado na Tabela 1, pode-se afirmar que não houve diferenças importantes em termos descritivos percentuais entre grupo com risco e sem risco psíquico, excetuando as que foram confirmadas na análise estatística (Tabela 2) relativas à experiência de prazer do bebê com objeto e da mãe em brincar com o filho, e a emergência mais tardia do brincar criativo no grupo com risco psíquico. Esse resultado também foi observado no estudo de Ambrós et al. (2017), em que se observou ausência de prazer na exploração com o objeto em um bebê com risco de autismo antes da intervenção educacional de base musical, prazer esse que começou a emergir a partir dessa intervenção.

De acordo com um estudo em Neurociências, o prazer na aprendizagem favorece o aumento das conexões sinápticas, ocasionando um processo mais positivo e eficaz. Por isso, a importância do brincar no cotidiano infantil para a maior efetividade do aprendizado, tendo em vista que a característica primordial do brincar livre é o prazer (SOUZA; ALVES, 2017). A ausência de prazer com o objeto e também na relação com o outro durante o brincar no grupo de risco psíquico, pode explicar a emergência tardia de brincadeiras criativas neste grupo. Para uso criativo as crianças precisam ser sustentadas subjetivamente pelo outro e exercitar o brincar (WINNICOTT, 1975; SABOIA et al., 2017).

Diante da utilização do objeto no seu uso funcional, foi possível evidenciar que há uma dificuldade em algumas crianças que possuem risco ao desenvolvimento infantil, aos 12 meses, porém essa manifestação apresentou uma evolução entre 18 e 24 meses. É importante salientar que essa condição foi fundamental para a constituição da capacidade da simbolização, pois mesmo antes da criança utlizar o objeto em uma atividade de faz-de-conta ela necessita utilizá-lo de modo funcional. Estudos nesse âmbito referem que essa aquisição é essencial para as habilidades simbólicas da criança, visto que a criança necessita ter essa experiência, para mais tarde ser utilizada como recurso para a representação do seu universo (COSTA et al., 2018). Por isso, a importância do adulto na interação lúdica com a criança pelos modelos que oportuniza para a imitação, mas, sobretudo, pelo prazer e investimento que manifesta, o que a literatura clássica de psicanálise já destacava (WINNICOTT, 1975).

Já com relação às construções criativas aos 24 meses, $50 \%$ das crianças as apresentaram. Isso faz supor o que já foi identificado em outros estudos, que é uma construção mais tardia também na criança típica e que dificuldades nesssa construção se acentuam na criança em risco (TAMANAHA et al., 2006; KLINGER; SOUZA, 2015).

No que se refere às categorias do brincar materno, quando observados os casos em risco psíquico, foi possível observar maior intrusividade e diretividade, bem como ritmo alterado na oferta dos brinquedos, além da já mencionada falta de prazer. As hipóteses explicativas podem relacionar-se a estados de humor materno ou dificuldades da criança, como a presença de risco para o autismo (MOTTA; LUCION; MANFRO, 2005; SAINT-GEORGES et al., 2011).

Em um estudo que investigou os efeitos da depressão materna na criança, foi observado que, durante a brincadeira, as mães apresentavam comportamento intrusivo e as crianças evitavam o olhar e a interação com ela (MOTTA; LUCION; MANFRO, 2005). Outro estudo mostra que essa redução de sintonia entre mãe e filho poderá refletir-se na criança por meio de dificuldades no desenvolvimento, como no brincar e na aquisição da linguagem, quando levadas em consideração as perspectivas interacionistas (CARLESSO; SOUZA; MORAES, 2014).

No caso do menino com risco claro de autismo - o bebê B6 -, foi possível observar que a mãe não era intrusiva nem diretiva e que apenas falava um pouco rápido para poder lidar com a falta de resposta do fiIho, mas esteve empenhada em "fisgá-lo" em todas as filmagens analisadas.

\section{CONCLUSÃO}

Podemos considerar que este estudo, desenvolvido a partir da análise dos vídeos, trouxe contribuições importantes para afirmar a relevância de observar a sustentação do adulto ao brincar infantil, sobretudo em relação ao prazer. Percebeu-se que as crianças com risco psíquico apresentaram menor prazer com o objeto e o seu uso criativo no brincar, e suas mães menor prazer em brincar com os filhos do que as díades sem risco psíquico. A diretividade e intrusividade maternas foram comuns em vários casos de risco psíquico. No caso de risco para autismo, a mãe esteve empenhada em tentar fisgar o filho na brincadeira.

\section{REFERÊNCIAS}

AMBRÓS, T. M. B.; CORREA, N. A.; OLIVEIRA, L. D.; SOUZA, A. P. R. A musicalização como intervenção precoce junto ao bebê com risco psíquico e seus familiares. Revista Latinoamericana de Psicopatologia Fundamental, São Paulo, v. 20, n. 3, p. 560-578, set. 2017. 
BAYLEY, N. Bayley Scales of Infant and Toddler Development. $3^{\text {rd }}$ ed. San Antonio, TX: Harcourt Assessment, 2006.

CAMPOS, S. D. F.; FIGUEIREDO, M. O.; MAZER-GONÇALVES, S. M.; SANTOS, E.; MARONESI, L. C. O brincar para o desenvolvimento do esquema corporal, orientação espacial e temporal: análise de uma intervenção. Cadernos Brasileiros de Terapia Ocupacional, São Paulo, v. 25, n. 2, p. 275-85, fev. 2017

CARLESSO, J. P. P.; SOUZA, A. P. R.; MORAES, A. B. Análise da relação entre depressão materna e indicadores clínicos de risco para o desenvolvimento infantil. Revista Cefac, São Paulo, v. 16, n. 2, p. 500-510, mar./abr. 2014.

COSTA, E. F.; CAVALCANTE, L. I. C.; LIMA, S. S.; ALENCAR, C. N. Pobreza familiar, desenvolvimento neuropsicomotor e brincadeiras. Revista Terapia Ocupacional Universidade São Paulo, São Paulo, v. 29, n. 2, p. 179-186, dez. 2018.

CRESTANI, A. H.; MATTANA, F.; MORAES, A. B.; SOUZA, A. P. R. Fatores socioeconômicos, obstétricos, demográficos e psicossociais como risco ao desenvolvimento infantil. Revista Cefac, São Paulo, v. 15, n. 4, p. 847-56, jul./ago. 2013.

CRESTANI, A. H.; MORAES, A. B.; SOUZA, A. P. R. Análise da associação entre índices de risco ao desenvolvimento infantil e produção de fala entre 13 e 16 meses. Revista Cefac, São Paulo, v. 17, n. 1, p. 169-176, jan./fev. 2015.

CORIAT, L.; JERUSALINSKY, A. N. Aspectos estruturais e instrumentais do desenvolvimento. In: Escritos da Criança, Porto Alegre: Centro Lídia Coriat, n. 4, 1996.

FONSECA, M. E. D.; SILVA, A. C. D. Concepções e uso do brincar na prática clínica de terapeutas ocupacionais. Cadernos Terapia Ocupacional - UFSCar, São Paulo, v. 23, n. 3, p. 589-597, maio 2015.

GRAÑA, C. A. Aquisição da linguagem nas crianças surdas e suas peculiaridades no uso do objeto transicional: um estudo de caso. Revista Eletrônica Contemporânea. Psicanálise e Transdisciplinaridade, Porto Alegre, n. 35, p. 143-153, jul./ dez. 2008.

KLINGER, E. F.; SOUZA, A. P. R. Análise clínica do brincar de crianças do espectro autista. Revista Distúrbios da Comunicação, São Paulo, v. 27, n. 1, p. 15-25, mar. 2015.

KRUEL, C. S.; SOUZA, A. P. R. O desenvolvimento do bebê e sua complexa relação com determinantes sociais de saúde. Psico-USF, São Paulo, v. 23, n. 1, p. 83-94, jan./mar. 2018.

KUPFER, M. C. M.; JERUSALINSKY, A. L.; BERNARDINO, L. M. F.; WANDERLEY, D.; ROCHA, P. S. B.; MOLINA, S. E.; SALES, L. M.; STELLIN, R.; PESARO, M. E. Predictive value of clinical risk indicators in child development: final results of a study based on psychoanalytic theory. Revista Latino-americana de Psicopatologia Fundamental, v. 13, n. 1, p. 31-52, mar. 2010.

MOTTA, G. M.; LUCION, A. B.; MANFRO, G. G. Efeitos da depressão materna no desenvolvimento neurobiológico e psicológico da criança. Revista Psiquiatria, Porto Alegre, v. 27, n. 2, p. 165-176, maio/ago. 2005.
MURATORI, F. O diagnóstico precoce no autismo: guia prático para pediatras. Salvador: Núcleo Interdisciplinar de Intervenção Precoce da Bahia, 2014.

NOVAES, B. C. A. C.; BARZAGHI, L. Avaliação fonoaudiológica de bebês e crianças com deficiência auditiva: função semiótica e linguagem. In: MARCHESAN, I. Q.; SILVA, H. J.; TOMÉ, M. C. Tratado das especialidades em fonoaudiologia. São Paulo: Guanabara Koogan, 2014. p. 1.005-1.013.

OLLIAC, B.; CRESPIN, G.; LAZNIK, M.-C.; EL GANOUNI, O. C. I.; SARRADET, J.-L.; BAUBY, C. Infant and dyadic assessment in early community-based screening for autism spectrum disorder with the PREAUT grid. PLoS One, v. 12, n. 12, p. 1-22. dez. 2017.

PERUZZOLO, D. L.; SOUZA, A. P. R. Uma hipótese de funcionamento psicomotor como estratégia clínica para tratamento de bebês em intervenção precoce. Cadernos Brasileiros de Terapia Ocupacional, São Paulo, v. 25, n. 2, p. 427-37, dez. 2017.

POLONIO, C. F.; FREIRE, R. M. A. C. O brincar na clínica fonoaudiológica. Revista Distúrbios da Comunicação, São Paulo, v. 20, n. 2, p. 267-78, ago. 2008.

SABOIA, C.; GOSMES, C.; VIODÉ, C.; GILLE, M.; OUSS, L.; GOLSE, B. Do brincar do bebê ao brincar da criança: um estudo sobre o processo de subjetivação da criança autista. Psicologia, Teoria e Pesquisa, Brasília, v. 33, p. 1-8, jun. 2017.

SAINT-GEORGES, C.; MAHDHAOUI, A.; CASSEL, R. S.; LAZNIK, M. C.; APICELLA, F. Do parents recognize autistic deviant behavior long before diagnosis? Taking into account interaction using computational methods. Plos One, v. 8, n. 10, p. 1-17, 2011.

SANT'ANNA, M. M. M.; BLASCOVI-ASSIS, S. M.; MAGALHÃES, L. C. Adaptação transcultural dos protocolos. Revista de Terapia Ocupacional Universidade de São Paulo, São Paulo, v. 19, n. 1, p. 34-47, abr. 2008.

SOUZA, A. P. R.; KLINGER, E. F.; BORIN, L.; MALDANER, R. $D$. A entrevista continuada na clínica de linguagem infantil. Fractal: Revista de Psicologia, Niterói/RJ, v. 21, n. 3, p. 601612, set./dez. 2009.

SOUZA, A. M. O.; ALVES, R. R. N. A neurociência na formação dos educadores e sua contribuição no processo de aprendizagem. Revista Psicopedagogia, São Paulo, v. 34, n. 105, p. 320-331, set. 2017.

TAMANAHA, A. C.; CHIARI, B. M.; PERISSINOTO, J.; PEDROMÔNICO, M. R. A. Atividade lúdica no autismo infantil. Revista Distúrbios da Comunicação, São Paulo, v. 18, n. 3, p. 307-312, dez. 2006.

VAN HOOGSTRATEN, A. M. R. J.; SOUZA, A. P. R.; MORAES, A. B. Indicadores clínicos de referência ao desenvolvimento infantil e sua relação com fatores obstétricos, psicossociais e sociodemográficos. Revista Saúde e Pesquisa, v. 11, n. 3, p. 589-601, ago. 2018a. 
VAN HOOGSTRATEN, A. M. R. J.; SOUZA, A. P. R.; MORAES, A. B. A complementaridade entre Sinais PREAUT e IRDI na análise do risco psíquico aos nove meses e sua relação com idade gestacional. CoDAS, São Paulo, v. 30, n. 5, p. 1-9 (e20170096), 2018b.

VENDRUSCOLO, J. F.; SOUZA, A. P. R. Intersubjetividade no olhar interdisciplinar sobre o brincar e a linguagem de sujeitos com risco psíquico. Revista Cefac, São Paulo, v. 17, n. 3, p. 707-719, maio/jun. 2015.

WINNICOTT, D. W. O brincar e a realidade. Rio de Janeiro: Imago, 1975. 